\title{
Comorbidity of migraine with ADHD in adults
}

Thomas Folkmann Hansen ${ }^{1,2,13^{*}}$, Louise K. Hoeffding ${ }^{3}$, Lisette Kogelman ${ }^{1}$, Thilde Marie Haspang ${ }^{1}$, Henrik Ullum ${ }^{3}$, Erik Sørensen ${ }^{3}$, Christian Erikstrup ${ }^{4}$, Ole Birger Pedersen ${ }^{5}$, Kaspar René Nielsen ${ }^{6}$, Henrik Hjalgrim,8, Helene M. Paarup ${ }^{9}$, Thomas Werge ${ }^{10,11,12}$ (D) and Kristoffer Burgdorf ${ }^{3}$

\begin{abstract}
Background: Migraine and Attention Deficit and Hyperactivity Disorder (ADHD) have been found to be associated in child and adolescent cohorts; however, the association has not been assessed in adults or otherwise healthy population. Assessing the comorbidity between ADHD and migraine may clarify the etiopathology of both diseases. Thus, the objective is to assess whether migraine (with and without visual disturbances) and ADHD are comorbid disorders.

Methods: Participants from the Danish Blood Donor Study ( $N=26,456$, age 18-65, 46\% female) were assessed for migraine and ADHD using the ASRS ver 1.1 clinically validated questionnaire and self-reported migraine in a crosssectional study. Logistic regression was used to examine the comorbidity between migraine and ADHD, and their associated endophenotypes.

Results: Migraine was strongly associated with $\mathrm{ADHD}(\mathrm{OR}=1.8,95 \% \mathrm{Cl}=1.5-2.1)$, (238/6152 vs 690/19,376). There was a significant interaction between age and gender, with comorbidity increasing with age and female sex. Posthoc analysis showed that migraine with visual disturbance was generally associated with a marginally higher risk of ADHD and this was independent of ADHD endophenotypes.

Conclusion: Migraine and ADHD were demonstrated to be comorbid disorders; the association with ADHD was most prominent for participants with migraine with visual disturbances. Future studies will elucidate which genetic and environmental factors contribute to migraine-ADHD comorbidity.
\end{abstract}

Keywords: Migraine, Attention deficiency and hyperactivity disorder, Comorbidity

\section{Background}

Migraine is a complex and multifactorial headache disorder with a lifetime prevalence of $16-18 \%$ [1-3]. Migraine is twice as prevalent in females, and onset is typically between adolescence and the late 50s [1-3]. According to the World Health Organization (WHO), migraine is the sixth most disabling disease in the world with high financial costs to society [4]. Response to acute treatment varies considerably and approximately $20 \%$ of the pharmacologically treated patients experience no symptom relief after medication [5]. There are two major endophenotypes in migraine: migraine

\footnotetext{
* Correspondence: Thomas.hansen@regionh.dk

${ }^{1}$ Danish Headache Center, Department of Neurology, Rigshospitalet Glostrup, University Hospital of Copenhagen, Copenhagen, Denmark

${ }^{2}$ Novo Nordisk Foundation Center for Protein Research, Faculty of Health and Medical Sciences, University of Copenhagen, Copenhagen, Denmark

Full list of author information is available at the end of the article
}

with or without aura. Aura is a sensory disturbance, which is predominantly seen as visual disturbances $(99 \%)$ with a subsequent headache or migraine [6,7].

Attention deficit and hyperactivity disorder (ADHD) is characterized by inappropriate levels of inattention, e.g., difficulty keeping attention, keeping track of details, and difficulty structuring trivial duties or following instructions, hyperactivity, e.g., speaks a lot, difficulty relaxing or sitting still, and impulsivity, e.g., often interrupts other people during conversations or answers a question before the question is finished [8]. In contrast to migraine, ADHD has an early onset and a pooled worldwide prevalence of $5.3 \%$ in child and adolescent populations [9]. The current treatment strategies do not completely remove the symptoms in both children and adults and approximately $30 \%$ of all patients

(c) The Author(s). 2018 Open Access This article is distributed under the terms of the Creative Commons Attribution 4.0 International License (http://creativecommons.org/licenses/by/4.0/), which permits unrestricted use, distribution, and 
do not respond to medical treatment or develop serious adverse reactions $[10,11]$.

It is well established that migraine is comorbid with psychiatric traits, in particular depressive and bipolar disorder [12,13], and that the comorbidity is partly explained by shared genetics [14]. More recently, the comorbidity between migraine and ADHD has also been assessed [15-18]. In adults, a clinical case-control study of ADHD ( $n=572 / 675)$ found an increased prevalence of migraine when compared to community controls [16], and subsequently the same investigators showed a positive association between prescription of anti-migraine and anti-ADHD drugs to adults in the total Norwegian population $(n>4$ mill) [17]. In line with this, Arruda et al. reported a higher prevalence of ADHD among children with migraine (5-12 years) than for non-headache individuals in a pediatric population cohort $(n=5671)$ [19]. According to the recently published meta-analysis including child and adolescence studies and the Fasmer et al. adult study, there is a positive association between migraine and ADHD with odds-ratio of $1.3[16,20]$.

Using a cross-sectional study of adults (age 18-65 years), we test the hypothesis that migraine is comorbid with ADHD in 26,456 participants using clinically validated questionnaires.

\section{Methods}

\section{Participants}

From November 2015 to September 2017 voluntary blood donors were recruited as part of the Danish Blood Donor Study (DBDS) (www.DBDS.dk). In brief, the DBDS was initiated in 2010 and is an ongoing prospective research cohort and biobank that recruits participants between 17 and 67 years of age from blood banks across Denmark $[21,22]$. Individuals in chronic medical treatment or frequent travelers to countries considered resulting in high-risk of blood disease are not allowed to participate. Approximately $95 \%$ of all invited individuals are consented to participate in DBDS [22]. At enrolment, each individual gives oral and written informed consent to participate in DBDS and subsequently answers a digital tablet-based questionnaire including a migraine (two questions) and an ADHD (18 questions) module. In total, 29,489 participants were recruited to the study. The study is approved by the Danish Data Protection Agency (2007-58-0015) and the Ethical Committee of Central Denmark (M-20090237). For further details about the DBDS platform and questionnaire, see Pedersen et al. [22] or Burgdorf et al. [21]

In total, 29,489 participants were given a questionnaire. We excluded 3033 individuals due to missing answers on either the SQM $(n=2057)$ or the ASRS items $(n=1108)$ of which $n=132$ were missing both. The excluded individuals did not differ significantly with respect to age (chi-square test, $P$-value $=0.24)$ compared to the study population. The excluded individuals were slightly older (median age: 44 years, IQR $=31-54$ years) when compared to the study population (median age: 42 years, IQR $=30$ 52 years) (Wilcoxon test, $P$-value $=3.7 \mathrm{e}-8)$. Importantly, the frequency of migraine in individuals excluded because of missing information in the ASRS questionnaire was similar to that of the study population (24.1\%). Further, the frequency of ADHD in individuals excluded because of missing items in the SQM questionnaire was similar to that of the study population $4.2 \%$.

\section{The migraine module}

The presence of migraine was evaluated by two questions from the population screening questionnaire for migraine (SQM). The participants were asked two questions ("Have you ever had migraine?" and "Have you ever had visual disturbances lasting 5-60 min followed by headache?") of the original SQM. Participants who had a positive response to either of the two questions were considered to have migraine and are referred as migraine cases in this study. Individuals with missing information or who answered "I don't know" were excluded. A detailed description of the SQM questionnaire can be found elsewhere [23]. In short, the SQM has previously been shown to identify $93 \%$ of those with migraine with aura and $75 \%$ of those with migraine without aura in a Danish setting [23]. Using the national prescription register, we found that $89.5 \%$ of those prescribed migraine-specific treatment, i.e. triptans ATC-codes N02CC01-7, are captured using these two questions.

\section{The ADHD module}

Current self-reported ADHD symptoms were assessed using the current national recommendation for clinical assessment of adults by using the ADHD Self-Report Scale v1.1 (ASRS) [24, 25] translated to Danish Dalsgaard et al. [26]. The ASRS consists of 18 items based on the Diagnostic and Statistical Manual of Mental Disorders fourth edition (DSM-IV) diagnostic criteria for ADHD and is the recommended version for clinical use in Denmark. Each of the 18 questions was scored on a five-point Likert scale ranging from never $=0$ to very often $=4$. In this study we use the optimal Kessler et al. 18-item ASRS scale score obtained by summarizing all items (total range of $0-72$ ) as the primary outcome. The ASRS has been validated in multiple countries using different populations [27-30]. The scale dichotomizes ADHD based upon all items for ADHD (having a score $>36$ ), inattentive subtype (items $1-4+7-11$, having a score $>23$ ), the hyperactivity-impulsivity subtype (items $5-6+12-18$, having a score $>23$ ), and the 6-item screening score (having a score $>13$ ) [28]. A more detailed description of the ASRS questionnaire can be found elsewhere [24]. 


\section{Statistical analysis}

The study population was described by numbers and percentages for categorical variables and as median and interquartile range (IQR) for continuous variables. Differences in distributions between participants with and without migraine and ADHD symptoms were analyzed using Fisher's exact test or Mann-Whitney/Wilcoxon test (age does not follow a normal distribution, thus non-parametric analysis is used).

Logistic regression was used to analyze the association between migraine and ADHD (dichotomous variables) in the study population, adjusting for age, sex, and the interaction between sex and age, with migraine as the dependent variable. We used a logistic regression model with a binary outcome of either migraine, migraine with visual disturbance, or migraine without visual disturbances. We did not include sampling weights, as these are not available for DBDS. We calculatedthe regression in two ways including age as a quantitative trait or as a categorical trait (10 year interval). We report the derived odds ratios (OR) and 95\% confidence intervals (CIs). A $P$-value $<0.05$ was considered statistically significant. Post-hoc analyses were performed using different thresholds of the ASRS score (from 0 and 52), and single ASRS items (data not shown). To check if the specified model is appropriate for the data, the predicted and observed residuals were inspected for each analysis and no issues were observed.

All statistical analyses were performed using the statistical package for $\mathrm{R}$ version 3.3.3: stat, basic, ggplot2, eeptools, cowplot, and GirdExtra.

\section{Results}

\section{Study population}

The population consisted of 26,456 participants (median age: 42 years, IQR $=30-52$ years) from the DBDS, of whom $24.2 \%$ screened positive for migraine (median age: 42 years, $\mathrm{IQR}=31-51$ years, female-to-male ratio: 1:0.6), 2.61\% screened positive for ADHD (median age: 29 years,
$\mathrm{IQR}=25-40$ years, female-to-male ratio: 1:1.4), and $0.90 \%$ reported having both migraine and ADHD (median age: 31 years, IQR $=24-41$ years, male-to-female ratio: 1:0.74), see Table 1 for the prevalence. There was a significant difference in the age and sex distributions for participants with either migraine or ADHD (Wilcoxon test and chi-square exact, $P<1 \mathrm{e}-15$ and $P<1 \mathrm{e}-15$, respectively) (Fig. 1), thus we included a correction for age, sex and interaction of age and sex in the model.

There was an association between migraine and ADHD symptoms with $\mathrm{OR}=1.81$ (95CI\%: $1.53-2.12, P=1.4 \mathrm{e}-14$ ) including corrections for age, sex and the interaction of age and sex as covariates (Table 2a). As expected, male sex is protective $(\mathrm{OR}=0.57)$, and increased age further increased protection with $\mathrm{OR}=9.99$ per year (Table $2 \mathrm{a}$ ). To ease literature comparison, we present the sex-stratified results (Table $2 b+c)$ and repeated the regression analysis using age bins (10 years), see Table 3 . The association was not explained by one specific item in the ASRS questionnaire (data not shown). The highest risk was found for migraine with visual disturbances and ADHD symptoms $(\mathrm{OR}=2.05$, 95CI\%: $1.55-2.68, P=3.3 \mathrm{e}-11)$. Using the national prescription register we did not find any difference in frequency of triptan purchases with and without ADHD symptoms (at least one purchase: $22.1 \%$ vs $23.2 \%, p=0.80$, at least 2 purchases: $13.7 \%$ vs $14.4 \%$, and at least 10 purchases: $3.2 \%$ vs $4.9 \%, p=0.39$ ).

The association between migraine and ADHD symptoms was statistically significant irrespective of the employed ASRS score threshold (Fig. 2a), with a tendency to increase with the ASRS score. The same results were observed for ADHD symptoms and migraine with visual disturbances (Fig. 2b), however; no association was detected for migraine without visual disturbances with ASRS scores below 10 and above 51 (Fig. 2c).

Migraine was associated with both ADHD endophenotypes (inattention and hyperactivity-impulsivity), with migraine with visual disturbances showing a marginally

Table 1 Characteristics of the study population $(N=26,456)$ with respect to migraine and ADHD symptoms

\begin{tabular}{|c|c|c|c|c|c|c|}
\hline \multirow[b]{2}{*}{ Description } & \multicolumn{5}{|l|}{ N } & \multirow[b]{2}{*}{$P$-value ${ }^{d}$} \\
\hline & \multicolumn{2}{|c|}{ Female $\left(\%{ }^{\mathrm{e}}\right)$} & \multirow{2}{*}{$\frac{\text { Male }}{14,209}$} & \multirow{2}{*}{$\frac{\text { Total }}{26,456}$} & \multirow{2}{*}{$\begin{array}{l}\left(\%{ }^{f}\right) \\
(100)\end{array}$} & \\
\hline The total study population & 12,247 & $(46.3)$ & & & & \\
\hline Migraine $^{a}$ & 4024 & $(63.0)$ & 2366 & 6390 & $(24.2)$ & $<0.001$ \\
\hline - Without visual disturbances & 2187 & $(62.0)$ & 1343 & 3530 & $(13.3)$ & $<0.001$ \\
\hline - With visual disturbances & 1832 & $(64.2)$ & 1019 & 2851 & $(10.8)$ & $<0.001$ \\
\hline$A D H D^{b}$ & 285 & $(41.3)$ & 405 & 690 & (2.6) & 0.0085 \\
\hline - Inattention & 83 & $(39.7)$ & 126 & 209 & $(0.79)$ & 0.06 \\
\hline - Hyperactivity-impulsivity & 67 & $(43.0)$ & 89 & 156 & $(0.59)$ & 0.42 \\
\hline - Screening items ${ }^{c}$ & 182 & $(26.7)$ & 400 & 682 & $(2.58)$ & $<0.001$ \\
\hline Migraine and ADHD & 137 & $(57.6)$ & 101 & 238 & $(0.90)$ & $<0.001$ \\
\hline
\end{tabular}

${ }^{\mathrm{a}}$ Symptoms of migraine was assessed by the SQM [19], ${ }^{\mathrm{b}}$ ADHD symptoms were assessed by the ASRS [20], ${ }^{\mathrm{c}}$ Screening as described by Kessing et al. [23], ${ }^{\mathrm{d}}$ Test of gender differences of total population and subgroup by chi-square test, ${ }^{e}$ percentage females of the subgrup, ${ }^{f}$ percentage of the total sample 


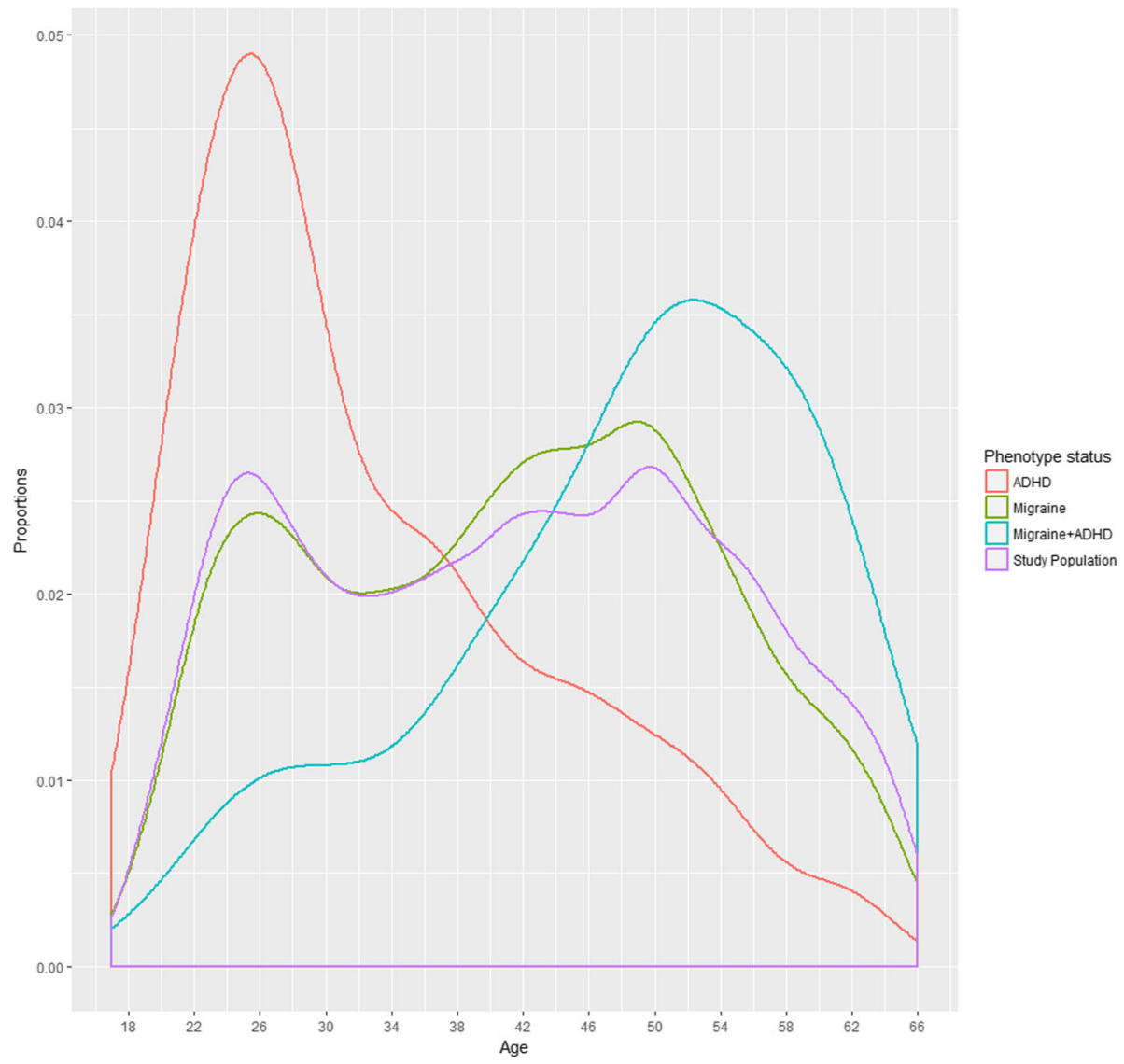

Fig. 1 Age distribution. The X-axis shows age from 17 to 66 years, the $Y$-axis shows the proportional distribution by age of the study population, colored according to phenotype status on the right

Table 2 Multivariable Logistic regression analysis

\begin{tabular}{|c|c|c|c|c|c|c|c|c|c|c|}
\hline \multirow{2}{*}{$\begin{array}{l}\text { Model } \\
\text { Outcome }\end{array}$} & \multirow[b]{2}{*}{ Variable } & \multicolumn{3}{|c|}{ a) All genders } & \multicolumn{3}{|c|}{ b) Females only } & \multicolumn{3}{|c|}{ c) Males only } \\
\hline & & $O R$ & Cl 95\% & P-value & $O R$ & Cl 95\% & $P$-value & $O R$ & $\mathrm{Cl} 95 \%$ & $P$-value \\
\hline \multirow[t]{4}{*}{ Migraine } & $\mathrm{ADHD}$ & 1.81 & $1.53-2.12$ & $<0.001$ & 2.01 & $1.58-2.54$ & $<0.001$ & 1.64 & $1.30-2.06$ & $<0.001$ \\
\hline & Age & 1.00 & $1.00-1.01$ & 0.001 & 1.01 & $1.00-1.01$ & $<0.001$ & 1.00 & $0.99-1.00$ & 0.051 \\
\hline & Gender (Male) & 0.57 & $0.47-0.69$ & $<0.001$ & & & & & & \\
\hline & Age:Gender (Male) & 0.99 & $0.99-0.99$ & $<0.001$ & & & & & & \\
\hline \multirow[t]{4}{*}{ With Visual Disturbances } & ADHD & 1.98 & $1.61-2.41$ & $<0.001$ & 2.05 & $1.55-2.68$ & $<0.001$ & 1.89 & $1.38-2.53$ & $<0.001$ \\
\hline & Age & 1.00 & $1.00-1.00$ & 0.84 & 1.00 & $1.00-1.00$ & 0.11 & 1.00 & $0.99-1.00$ & 0.11 \\
\hline & Gender (Male) & 0.53 & $0.40-0.69$ & $<0.001$ & & & & & & \\
\hline & Age:Gender (Male) & 1.00 & $0.99-1.00$ & 0.16 & & & & & & \\
\hline \multirow[t]{4}{*}{ Without Visual Disturbances } & ADHD & 1.52 & $1.22-1.88$ & $<0.001$ & 1.69 & $1.24-2.27$ & $<0.001$ & 1.37 & $0.99-1.86$ & 0.047 \\
\hline & Age & 1.01 & $1.00-1.01$ & $<0.001$ & 1.01 & $1.00-1.01$ & $<0.001$ & 1.00 & $0.99-1.00$ & 0.23 \\
\hline & Gender (Male) & 0.63 & $0.49-0.82$ & $<0.001$ & & & & & & \\
\hline & Age:Gender (Male) & 0.99 & $0.98-1.00$ & $<0.001$ & & & & & & \\
\hline
\end{tabular}


Table 3 Multivariable logistic regression analysis

\begin{tabular}{|c|c|c|c|c|}
\hline Outcome & Variable & $O R$ & Cl 95\% & $P$-value \\
\hline \multirow[t]{11}{*}{ Migraine } & ADHD & 1,86 & $1,58-2,19$ & $<0.001$ \\
\hline & Age $3 X^{a}$ & 1,34 & $1,20-1,51$ & $<0.001$ \\
\hline & Age $4 X^{a}$ & 1,59 & $1,43-1,76$ & $<0.001$ \\
\hline & Age $5 X^{a}$ & 1,27 & $1,14-1,42$ & $<0.001$ \\
\hline & Age $60+{ }^{a}$ & 0,98 & $0,84-1,15$ & 0.80 \\
\hline & Gender (Male) & 0,49 & $0,44-0,56$ & $<0.001$ \\
\hline & \multicolumn{4}{|c|}{ Gender (Male) interaction with: } \\
\hline & Age $3 X^{a}$ & 0,78 & $0,66-0,93$ & 0.007 \\
\hline & Age $4 X^{a}$ & 0,75 & $0,63-0,88$ & $<0.001$ \\
\hline & Age $5 X^{a}$ & 0,75 & $0,63-0,89$ & 0.0013 \\
\hline & Age $60+{ }^{a}$ & 0,84 & $0,66-1,07$ & 0.16 \\
\hline \multirow[t]{11}{*}{ With Visual Disturbances } & ADHD & 2,01 & $1,63-2,45$ & $<0.001$ \\
\hline & Age $3 X^{a}$ & 1,13 & $0,97-1,31$ & 0.110 \\
\hline & Age $4 X^{a}$ & 1,20 & $1,05-1,38$ & 0.0095 \\
\hline & Age $5 X^{a}$ & 1,13 & $0,98-1,31$ & 0.090 \\
\hline & Age $60+{ }^{a}$ & 0,78 & $0,63-0,97$ & 0.028 \\
\hline & Gender (Male) & 0,49 & $0,41-0,57$ & $<0.001$ \\
\hline & \multicolumn{4}{|c|}{ Gender (Male) interaction with: } \\
\hline & Age $3 X^{a}$ & 0,90 & $0,71-1,15$ & 0.41 \\
\hline & Age $4 X^{a}$ & 0,83 & $0,66-1,05$ & 0.13 \\
\hline & Age $5 X^{a}$ & 0,79 & $0,62-1,01$ & 0.06 \\
\hline & Age $60+{ }^{a}$ & 1,12 & $0,80-1,57$ & 0.5 \\
\hline \multirow[t]{11}{*}{ Without Visual Disturbances } & $\mathrm{ADHD}$ & 1,59 & $1,28-1,97$ & $<0.001$ \\
\hline & Age $3 X^{a}$ & 1,47 & $1,27-1,70$ & $<0.001$ \\
\hline & Age $4 X^{a}$ & 1,81 & $1,59-2,07$ & $<0.001$ \\
\hline & Age $5 X^{a}$ & 1,34 & $1,16-1,54$ & $<0.001$ \\
\hline & Age $60+{ }^{a}$ & 1,15 & $0,94-1,39$ & 0.16 \\
\hline & Gender (Male) & 0,53 & $0,46-0,63$ & $<0.001$ \\
\hline & \multicolumn{4}{|c|}{ Gender (Male) interaction with: } \\
\hline & Age $3 X^{a}$ & 0,73 & $0,58-0,92$ & 0.0069 \\
\hline & Age $4 X^{a}$ & 0,72 & $0,59-0,89$ & 0.0026 \\
\hline & Age $5 X^{a}$ & 0,75 & $0,60-0,93$ & 0.011 \\
\hline & Age $60+{ }^{a}$ & 0,69 & $0,50-0,94$ & 0.021 \\
\hline
\end{tabular}

${ }^{\mathrm{a}}$ Reference is age $<30$

larger effect than migraine without visual disturbances, notably with overlapping confidence intervals (Fig. 3).

\section{Discussion}

We address the comorbidity of migraine and ADHD symptoms in a healthy population of 29,489 adults using two clinically validated questionnaires (SQM and ASRS). Our results show a strong and statistically significant comorbidity between the two disorders which was irrespective of the threshold (i.e., not restricted to the commonly used ASRS score threshold of 37 (Fig. 2). The regression model clearly shows that being male protects against migraine and increased age is further protective as seen in the interaction between age and sex (Table 2). Stratified analyses suggested that the observed comorbidity was more pronounced in migraineurs experiencing visual disturbances; however, no differences in association with migraine were seen for the two ADHD endophenotypes (inattention and hyperactivity-impulsivity).

The current study significantly supplements the sparse literature regarding the comorbidity between migraine and ADHD in adults by using a large, healthy study population of individuals who have not been exposed to chronic treatment for migraine or for ADHD. It supports the meta-analysis by Salem et al., showing OR of 1.3, consisting primarily of child and adolescence studies. This meta-analysis cohort consisted of a clinical case-control cohort, $(n=572)$ with ADHD [16], and a cross-sectional study using prescription data on anti-migraine and anti-ADHD drugs from the entire Norwegian population [17]. Thus, the comorbidity between migraine and ADHD seems present both in and out of a clinical setting. The origin of the comorbidity is not obvious and typical prognostic features such as the age of onset, and the female-to-male ratio of the two diseases are somewhat contradicting. It has previously been suggested that the co-occurrence of migraine and ADHD originates from common pathophysiological mechanisms potentially related to dysfunctions in the dopaminergic system $[16,17,31]$. This arises because many of the migraine symptoms, including prodromal symptoms, can be provoked with dopamine receptor stimulation, and some can even be quantified in rat models with dopaminergic activiation [31]. Dopamine has long been thought to be involved in ADHD pathology, and the effective ADHD drug, methylphenidate, acts by inhibiting dopamine reuptake. However, the comorbidity could also be more complex because of common co-morbidities of other psychiatric disorders such as anxiety and mood disorders $[13,32-36]$. Their etiological comorbidity may arise because of pleiotropic factors. This has recently been supported by Antilla et al., showing a significant genetic correlation between migraine and ADHD [37]. Interestingly, major depressive disorder was also found to significantly correlate with both migraine and ADHD suggesting that common pleiotropic factors exist.

The observed prevalence of migraine and ADHD (34.7\%) was higher than reported by Fasmer et al. $(28.3 \%)$ in a sample of ADHD patients with similar age and sex distribution [16]. However, there is an anecdote among headache individuals with headache that donating blood gives symptom relief, which could explain the frequency of migraine, i.e. bloodletting by phlebotomy. Furthermore, we used self-reported ADHD rather than formal clinical diagnoses in our analysis, which may influence the results with false positive and negative cases. Despite these methodological 


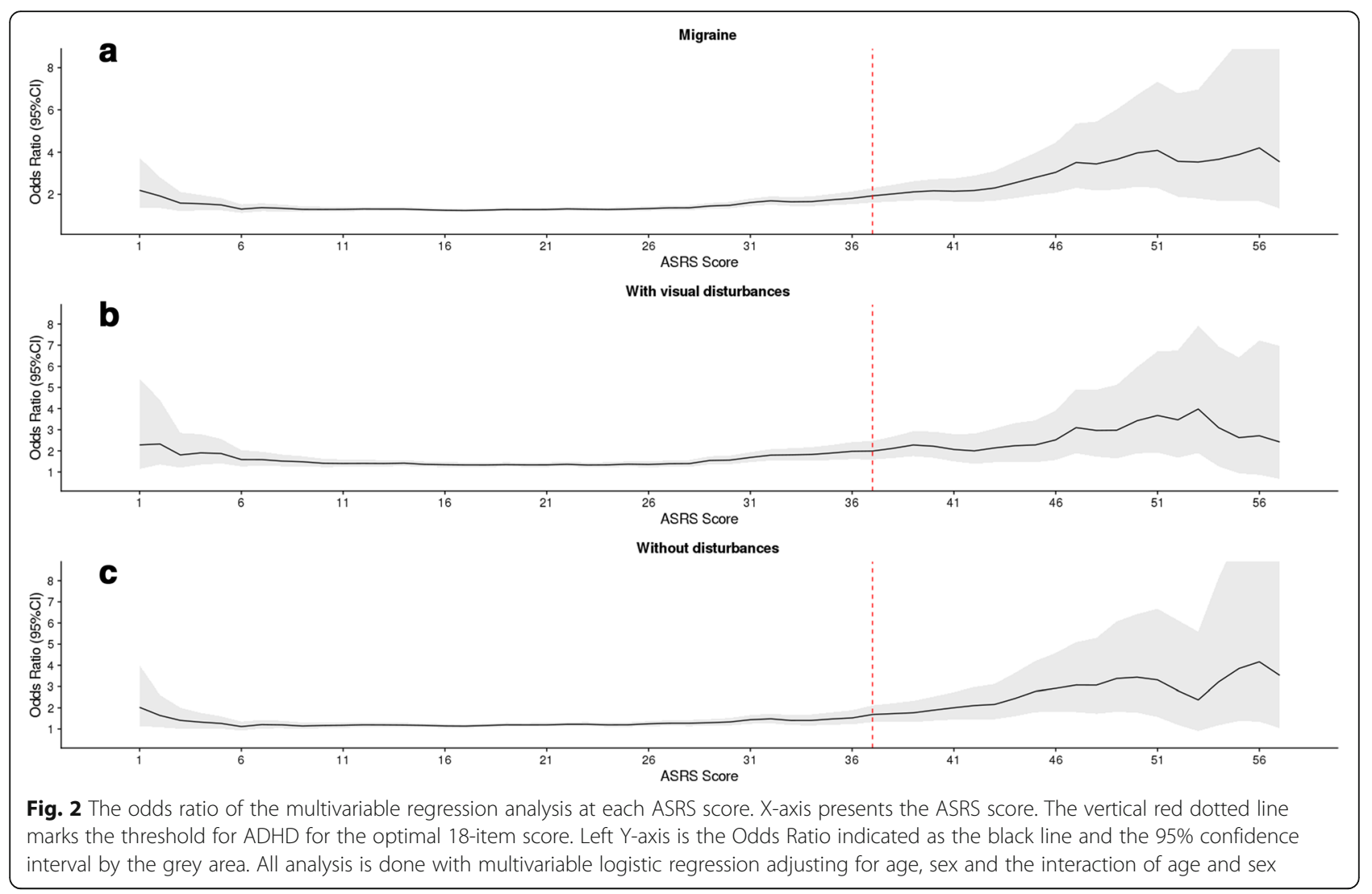

differences, we found the prevalence of self-reported migraine and ADHD symptoms in males ( $24 \%$ vs. $23 \%)$ to be like that reported by Fasmer et al. [16].

We found that the comorbidity between migraine and ADHD was most prevalent among participants peaking at 52 to 53 years of age, and in the 40 decade compared to the 17-29 age group, which is somewhat inversely correlated with the age distribution of ADHD symptoms in the study population (Fig. 1). This could imply that the manifestations of comorbid migraine and ADHD occur rather late in life when compared to ADHD in general, or that ADHD symptoms mask the presence of migraine in the younger participants. Similar results have been reported by Fasmer et al. [17] using simultaneous
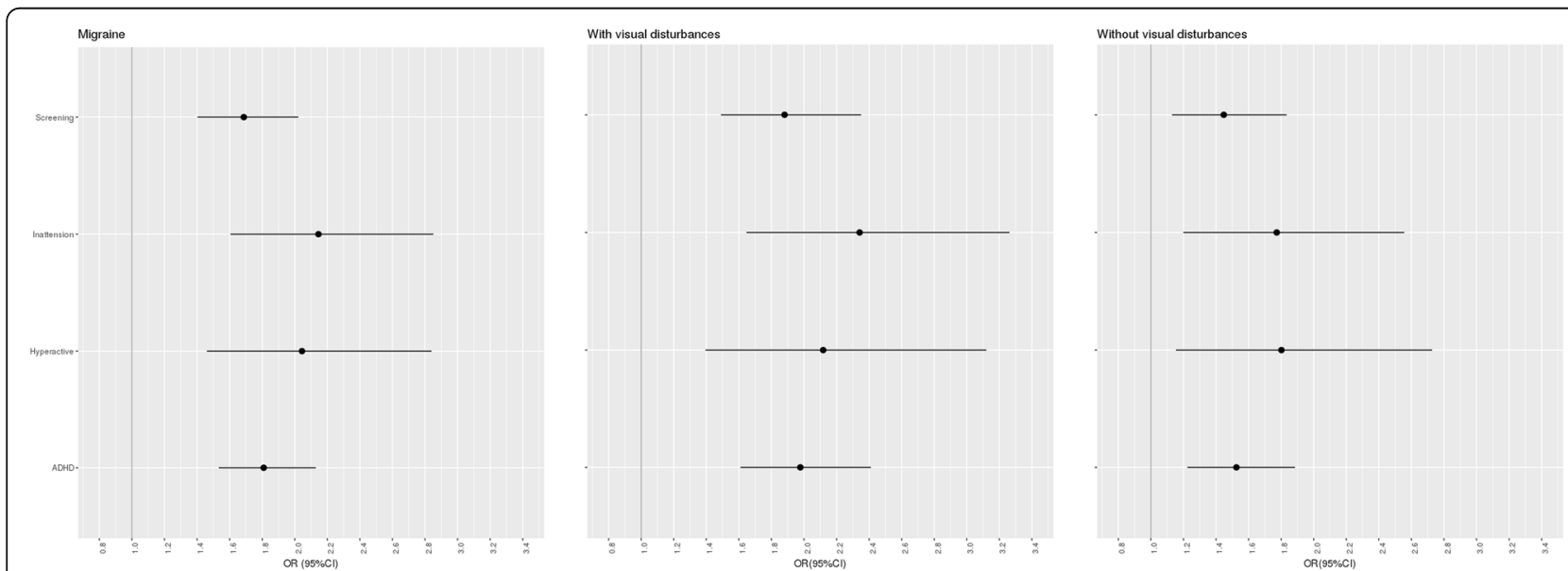

Fig. 3 Analysis of ADHD and Migraine endophenotypes. X-axes are odds ratio (black dot) and 95\% confidence intervals (black lines) with a grey vertical line indicating an odds ratio of 1 . The three graphs display migraine, and migraine with and without visual disturbances. The $Y$-axis displays the ADHD and two ADHD endophenotypes 
prescriptions of anti-migraine and anti-ADHD medication as a proxy for comorbidity. However, this was not true for the 10-19 years age group, suggesting that ADHD among adolescents may have no comorbidity with migraine and thus having a distinct etiopathology or, as previously mentioned, there is a masking of migraine symptoms in young individuals with ADHD. The notion of a different etiopathology among ADHD patients is suggested by Johansson et al. (Johansson et al. 2008), showing that susceptibility genes differ between persistent and juvenile ADHD [38]. Furthermore, the transition of ADHD symptoms from childhood to adulthood is well recognized where the hyperactivity-impulsivity often becomes less prominent.

We did not detect a specific association between any ADHD endophenotypes and migraine which is congruent with previous reports for children, e.g., Pakainis et al. and Arruda et al $[19,39]$ It is noteworthy that we do not see a large difference between ADHD inattention and hyperactive endophenotype. Although speculative, the smaller difference between hyperactive and inattention endophenotype in the study cohort could reflect that the inattention is more often referred to treatment and thus are not permitted to donate blood [40].

Participants reporting migraine preceded by visual disturbances (migraine with visual aura symptoms) were more often affected by co-occurring ADHD symptoms when compared to participants reporting no visual disturbances and combined (Table 2, Fig. 2). No obvious shared mechanism between visual disturbances and ADHD symptoms is known. The neurovascular phenomenon cortical depression spreading is suggested as the pathophysiology of aura symptoms in migraine patients [41], however, there are no published studies on ADHD patients. Ophthalmologic disturbances appear to be more frequent in patients diagnosed with ADHD [42], however, it is very speculative whether this could explain the observed comorbidity and further studies are needed.

The strength of the study is the large sample size and that chronic treatment of migraine and ADHD do not influence the results, e.g., treatment-induced migraine attacks. Furthermore, we used validated questionnaires to assess migraine and ADHD symptoms. In accordance with Danish clinical guides we use the recommended version of ASRS to assess ADHD. While a new version based on DSM V exists, a recent study found almost identical specificity and sensitivity of the two versions [43]. Furthermore, we show that $89 \%$ of individuals using triptans are captured, and the prevalence of triptan users in migraineurs with and without ADHD symptoms is the same. When interpreting the results, it is important to take into consideration that the study population is a healthy donor population, presumably producing a conservative estimate of the association as individuals exposed to chronic medication or chronic illness are excluded as donors. Further, we suggest carrying out longitudinal cohort and twin studies to assess causality.

\section{Conclusion}

We demonstrate a significant corbobidity between migraine and ADHD in adults, and this is most prominent for participants with migraine with visual disturbances. These results contribute to the understanding of genetic correlation seen between ADHD and migraine and seeds future studies that will elucidate which genetic and environmental factors contribute to migraine-ADHD comorbidity.

\section{Article highlights}

- This study examined the association between migraine and ADHD in a large adult population

- There is a strong association between migraine and ADHD (odds ratio $=1.8,95 \% \mathrm{CI}=1.5-2.1$ )

- The association between migraine and ADHD seems strongest for individuals with visual disturbances

\section{Abbreviations \\ 95\%C195: Confidence interval; ADHD : Attention Deficit and Hyperactivity Disorder; ASRS: ADHD Self-Report Scale; IQR: Interquartile range; OR: Odss Ratio; SQM: Screening questionnaire for migraine; WHO: World Health Organization}

\section{Acknowledgments}

We acknowledge the Danish blood donors and the staff at the Danish blood banks involved in the present study. We thank Shantel Weinsheimer for reviewing the final manuscript.

\section{Funding}

This work was supported by RegionH research foundation (R129-A3973 to Dr. Hansen); Candy foundation CEHEAD (Prof Jes Olesen, Co-PI Dr. Hansen); the Lundbeck Foundation, Denmark under Grant (R219-2016-1030 to Dr. Hoeffding); The Danish Council for Independent Research - Medical Sciences under Grant (1333-00275A to Dr. Burgdorf and 09-069412); The Danish Administrative Regions; The Danish Administrative Regions' Bio- and Genome Bank; and The Danish Blood Donor Research Foundation (Bloddonorernes Forskningsfond). The funders had no role in study design, data collection, and analysis, decision to publish, or preparation of the manuscript.

\section{Availability of data and materials}

The data that support the findings of this study are available from DBDS but restrictions apply to the availability of these data, which were used under license for the current study, and so are not publicly available. Data are however available from the authors upon reasonable request and with permission of DBDS steering committee and the Ethical Committee of Central Denmark.

\section{Authors contributions}

TFH, LKH, study design and analysis. LK and TMH statistical design and analysis. $H U, E S, C E, O B P, K R N, H H, H M P, T W$, and $K B$ study design. All authors contributed to creating this manuscript and approved the final version.

\section{Ethics approval and consent to participate}

The study is approved by the Danish Data Protection Agency (2007-58-0015) and the Ethical Committee of Central Denmark (M-20090237). All participants gave informed oral and written consent to participate.

Consent for publication

NA 


\section{Competing interests}

TW: has served as a lecturer for and consultant to $\mathrm{H}$. Lundbeck A/S. $\mathrm{TFH}, \mathrm{LKH}, \mathrm{KB}, \mathrm{LK}, \mathrm{TMH}, \mathrm{HH}, \mathrm{HMP}, \mathrm{KRN}, \mathrm{OBP}, \mathrm{CE}, \mathrm{ES}, \mathrm{HU}$ and TW reports no competing interest.

\section{Publisher's Note}

Springer Nature remains neutral with regard to jurisdictional claims in published maps and institutional affiliations.

\section{Author details}

'Danish Headache Center, Department of Neurology, Rigshospitalet Glostrup, University Hospital of Copenhagen, Copenhagen, Denmark. ${ }^{2}$ Novo Nordisk Foundation Center for Protein Research, Faculty of Health and Medical Sciences, University of Copenhagen, Copenhagen, Denmark. ${ }^{3}$ Department of Clinical Immunology, the Blood Bank, Rigshospitalet, University Hospital of Copenhagen, Copenhagen, Denmark. ${ }^{4}$ Department of Clinical Immunology, Aarhus University Hospital, Aarhus, Denmark. ${ }^{5}$ Department of Clinical Immunology, Naestved Hospital, Naestved, Denmark. ${ }^{6}$ Department of Clinical Immunology, Aalborg University Hospital, Aalborg, Denmark. ${ }^{7}$ Department of Epidemiology Research, Statens Serum Institut, Copenhagen, Denmark. ${ }^{8}$ Department of Hematology, Copenhagen University Hospital, Rigshospitalet, Copenhagen, Denmark. ${ }^{9}$ Department of Clinical Immunology, Odense University Hospital, Odense, Denmark. ${ }^{10}$ Institute of Biological Psychiatry, Mental Health Centre Sct. Hans, Copenhagen University Hospital, Roskilde, Denmark. ${ }^{11}$ Department of Clinical Medicine, University of Copenhagen, Copenhagen, Denmark. ${ }^{12}$ The Lundbeck Foundation Initiative for Integrative Psychiatric Research, iPSYCH, Copenhagen, Denmark. ${ }^{13}$ Danish Headache Center, Neurological department, Copenhagen University Hospital, Nordre Ringevej 69, DK-2600 Glostrup, Denmark.

\section{Received: 20 June 2018 Accepted: 11 September 2018}

\section{Published online: 16 October 2018}

\section{References}

1. Dahlof C, Linde M. One-year prevalence of migraine in Sweden: a population-based study in adults. Cephalalgia. 2001;21:664-71.

2. Hagen K, Zwart JA, Vatten L, Stovner LJ, Bovim G. Prevalence of migraine and non-migrainous headache--head-HUNT, a large population-based study. Cephalalgia. 2000;20:900-6.

3. Russell MB, Rasmussen BK, Thorvaldsen P, Olesen J. Prevalence and sex-ratio of the subtypes of migraine. Int J Epidemiol. 1995;24:612-8.

4. Gustavsson A, Svensson M, Jacobi F, et al. Cost of disorders of the brain in Europe 2010. Eur Neuropsychopharmacol. 2011;21:718-79.

5. Oldman AD, Smith LA, McQuay HJ, Moore RA. Pharmacological treatments for acute migraine: quantitative systematic review. Pain. 2002;97:247-57.

6. Headache Classification Committee of the International Headache Society (IHS) The International Classification of Headache Disorders, 3rd edition. Cephalalgia 2018;38:1-211.

7. Russell MB, Olesen J. A nosographic analysis of the migraine aura in a general population. Brain. 1996;119:355-61.

8. Organization WH. International Statistical Classification of Diseases and Related Health Problems: tenth revision-Version for 2007. http://www.who. int/classifications/icd/en/. Accessed 1 Dec 2017.

9. Polanczyk G, de Lima MS, Horta BL, Biederman J, Rohde LA. The worldwide prevalence of ADHD: a systematic review and metaregression analysis. Am J Psychiatry. 2007;164:942-8.

10. Maia CR, Cortese $S$, Caye A, et al. Long-term efficacy of methylphenidate immediate-release for the treatment of childhood ADHD. J Atten Disord. 2017;21:3-13.

11. Spencer T, Biederman J, Wilens T, et al. A large, double-blind, randomized clinical trial of methylphenidate in the treatment of adults with attentiondeficit/hyperactivity disorder. Biol Psychiatry. 2005;57:456-63.

12. Antonaci F, Nappi G, Galli F, Manzoni GC, Calabresi P, Costa A. Migraine and psychiatric comorbidity: a review of clinical findings. I Headache Pain. 2011;12:115-25

13. Jette N, Patten S, Williams J, Becker W, Wiebe S. Comorbidity of migraine and psychiatric disorders--a national population-based study. Headache. 2008:48:501-16

14. Yang $Y$, Zhao H, Heath AC, Madden PA, Martin NG, Nyholt DR. Shared genetic factors underlie migraine and depression. Twin Res Hum Genet. 2016;19:341-50.
15. Arruda MA, Guidetti V, Galli F, Albuquerque RC, Bigal ME. Migraine, tensiontype headache, and attention-deficit/hyperactivity disorder in childhood: a population-based study. Postgrad Med. 2010;122:18-26.

16. Fasmer OB, Halmoy A, Oedegaard KJ, Haavik J. Adult attention deficit hyperactivity disorder is associated with migraine headaches. Eur Arch Psychiatry Clin Neurosci. 2011;261:595-602.

17. Fasmer OB, Riise T, Lund A, Dilsaver SC, Hundal O, Oedegaard KJ. Comorbidity of migraine with ADHD. J Atten Disord. 2012;16:339-45.

18. Instanes JT, Klungsoyr K, Halmoy A, Fasmer OB, Haavik J. Adult ADHD and comorbid somatic disease: a systematic literature review. J Atten Disord. 2016.

19. Arruda MA, Arruda R, Guidetti V, Bigal ME. ADHD is comorbid to migraine in childhood: a population-based study. J Atten Disord. 2017: 1087054717710767. https://www.ncbi.nlm.nih.gov/pubmed/28587507.

20. Salem H, Vivas D, Cao F, Kazimi IF, Teixeira AL, Zeni CP. ADHD is associated with migraine: a systematic review and meta-analysis. Eur Child Adolesc Psychiatry. 2018;27(3):267-77

21. Burgdorf KS, Felsted N, Mikkelsen S, et al. Digital questionnaire platform in the Danish blood donor study. Comput Methods Prog Biomed. 2016:135:101-4.

22. Pedersen OB, Erikstrup C, Kotze SR, et al. The Danish blood donor study: a large, prospective cohort and biobank for medical research. Vox Sang. 2012;102:271

23. Gervil M, Ulrich V, Olesen J, Russell MB. Screening for migraine in the general population: validation of a simple questionnaire. Cephalalgia. 1998;18:342-8.

24. Kessler RC, Adler L, Ames M, et al. The World Health Organization adult ADHD self-report scale (ASRS): a short screening scale for use in the general population. Psychol Med. 2005;35:245-56.

25. NKR: Udredning og behandling af ADHD hos voksne. at https://www.sst.dk/ da/udgivelser/2015/nkr-adhd-hos-voksne. Accessed 1 Dec 2017.

26. Poulsen L, Jorgensen SL, Dalsgaard S, Bilenberg N. Danish standardization of the attention deficit hyperactivity disorder rating scale. Ugeskr Laeger. 2009;171:1500-4.

27. Adler LA, Spencer T, Faraone SV, et al. Validity of pilot adult ADHD selfreport scale (ASRS) to rate adult ADHD symptoms. Ann Clin Psychiatry. 2006;18:145-8.

28. Kessler RC, Adler LA, Gruber MJ, Sarawate CA, Spencer T, Van Brunt DL. Validity of the World Health Organization adult ADHD self-report scale (ASRS) screener in a representative sample of health plan members. Int J Methods Psychiatr Res. 2007;16:52-65.

29. Kim JH, Lee EH, Joung YS. The WHO adult ADHD self-report scale: reliability and validity of the Korean version. Psychiatry Investig. 2013;10:41-6.

30. Sonnby K, Skordas K, Olofsdotter S, Vadlin S, Nilsson KW, Ramklint M. Validation of the World Health Organization adult ADHD self-report scale for adolescents. Nord J Psychiatry. 2015;69:216-23.

31. Emilien G, Maloteaux JM, Geurts M, Hoogenberg K, Cragg S. Dopamine receptors--physiological understanding to therapeutic intervention potential. Pharmacol Ther. 1999:84:133-56.

32. Fasmer $\mathrm{OB}$. The prevalence of migraine in patients with bipolar and unipolar affective disorders. Cephalalgia. 2001;21:894-9.

33. Fasmer $\mathrm{OB}$, Oedegaard KJ. Clinical characteristics of patients with major affective disorders and comorbid migraine. World J Biol Psychiatry. 2001;2:149-55.

34. Low NC, Du Fort GG, Cervantes P. Prevalence, clinical correlates, and treatment of migraine in bipolar disorder. Headache. 2003;43:940-9.

35. Breslau N, Merikangas K, Bowden CL. Comorbidity of migraine and major affective disorders. Neurology. 1994;44:S17-22.

36. d'Onofrio F, Barbanti $P$, Petretta $V$, et al. Migraine and movement disorders. Neurol Sci. 2012;33(Suppl 1):S55-9.

37. Brainstorm C, Anttila V, Bulik-Sullivan B, et al. Analysis of shared heritability in common disorders of the brain. Science. 2018:360.

38. Johansson S, Halleland H, Halmoy A, et al. Genetic analyses of dopamine related genes in adult $\mathrm{ADHD}$ patients suggest an association with the DRD5-microsatellite repeat, but not with DRD4 or SLC6A3 VNTRs. Am J Med Genet B Neuropsychiatr Genet. 2008;147B:1470-5.

39. Pakalnis A, Gibson J, Colvin A. Comorbidity of psychiatric and behavioral disorders in pediatric migraine. Headache. 2005:45:590-6.

40. Millstein RB, Wilens TE, Biederman J, Spencer TJ. Presenting ADHD symptoms and subtypes in clinically referred adults with ADHD. J Atten Disord. 1997;2:159-66

41. Lauritzen M. Pathophysiology of the migraine aura. The spreading depression theory. Brain. 1994;117(Pt 1):199-210. 
42. Gronlund MA, Aring E, Landgren M, Hellstrom A. Visual function and ocular features in children and adolescents with attention deficit hyperactivity disorder, with and without treatment with stimulants. Eye (Lond). 2007;21: 494-502.

43. Bastiaens L, Galus J. Comparison of the adult ADHD self report scale screener for DSM-IV and DSM-5 in a dually diagnosed correctional population. Psychiatr Q. 2018:89:505-10.

Ready to submit your research? Choose BMC and benefit from:

- fast, convenient online submission

- thorough peer review by experienced researchers in your field

- rapid publication on acceptance

- support for research data, including large and complex data types

- gold Open Access which fosters wider collaboration and increased citations

- maximum visibility for your research: over $100 \mathrm{M}$ website views per year

At BMC, research is always in progress.

Learn more biomedcentral.com/submissions 